7th International Symposium on Superalloy 718 and Derivatives Edited by: E.A. Ott, J.R. Groh, A. Banik, I. Dempster, T.P. Gabb, R. Helmink, X. Liu, A. Mitchell, G.P. Sjöberg, and A. Wusatowska-Sarnek TMS (The Minerals, Metals \& Materials Society), 2010

\title{
SURFACE MODIFICATION OF INCONEL 718 SUPERALLOY BY PLASMA IMMERSION ION IMPLANTATION
}

\author{
A.C.O. Hirschmann ${ }^{1 *}$, M.M.Silva ${ }^{2}$, C. Moura Neto ${ }^{2}$, M. Ueda ${ }^{3}$, C.B. Mello ${ }^{3}$, M.J.R. Barboza ${ }^{4}$, A. \\ A. Couto ${ }^{5}$ \\ ${ }^{1}$ Vale Soluções em Energia (VSE) - Sao Jose dos Campos/SP Brazil \\ ${ }^{2}$ Instituto Tecnológico de Aeronautica- ITA Sao Jose dos Campos/SP Brazil \\ ${ }^{3}$ Laboratorio de Plasma, Instituto Nacional de Pesquisas Espaciais-INPE, Sao Jose dos Campos/SP Brazil \\ ${ }^{4}$ Escola de Engenharia de Lorena, EEL-USP, Lorena/SP Brazil \\ ${ }^{5}$ Instituto de Pesquisas Energética e Nucleares, IPEN, Sao Paulo/SP, Brazil
}

Keywords: Superalloy; Inconel 718; Plasma immersion ion implantation; Pin-on-disk wear.

\begin{abstract}
Superalloy are alloys developed for elevated temperatures applications, where relatively severe mechanical stressing is found, and a high surface stability is frequently required. Improvements in the surface properties of a wide range of alloys have been obtained by the implantation of nitrogen while field test results for industrial tools and components from a diverse range of applications have been positive. The objective of this work is to improve the mechanical surface properties of Inconel 718 by PIII (Plasma Immersion Ion Implantation - PIII). In these experiments, samples of Inconel 718 without heat treatment are used. Nitrogen ions in Inconel samples were implanted: a) for a period of one hour, and b) for a period of 3 hours. Tribological properties of PIII treated samples were compared with the ones for untreated samples are compared. The best result is obtained for the samples treated for 3 hours after 5000 cycles of an unlubricated pin-on-disk test, with very little wear.
\end{abstract}

\section{Introduction}

Nickel superalloys are part of a family of metallic materials that are used at elevated temperatures. Inconel 718 derives its strength from solid solutions of alloying elements and, to a large extent, from precipitates within a solid solution matrix. Superalloys maintain their good mechanical properties up to temperatures close to their melting points and present good resistance to oxidation. Among Ni-base superalloys, Inconel 718 is predominantly used in high temperature applications due to its highly satisfactory price/overall performance ratio, and good mechanical properties with excellent weldability $[1,2]$. Gas turbine engines are the major applications of this alloy. However, its mechanical properties are degraded at temperatures above $650^{\circ} \mathrm{C}$ [3-8].

Nitriding of superalloys has been less explored than nitriding of austenitic (FCC) stainless steels despite the similarity in structure and shortcomings (susceptibility to localized corrosion and poor tribological performance) for the two alloy systems $[9,10]$.

It is now well known that low temperature $\left(<500^{\circ} \mathrm{C}\right)$ nitriding of austenitic stainless steels can produce a supersaturated FCC phase that combines high hardness and good corrosion resistance (above $500^{\circ} \mathrm{C}$ hardness is increased at the expense of corrosion resistance). This phase is known as s-phase or expanded austenite [11-13]. Due to the similarities between the austenitic 
stainless steels and $\mathrm{Ni}-\mathrm{Cr}$ alloys, it is reasonable to expect that an analogous phase will be formed in $\mathrm{Ni}-\mathrm{Cr}$ alloys also.

Williamson et al. formed just such a phase (also termed expanded austenite $\gamma_{\mathrm{N}}$ ) in a binary $\mathrm{Ni}-20 \mathrm{Cr}$ alloy by low energy ion implantation at $400^{\circ} \mathrm{C}$, simultaneously confirming the possibility of a $\gamma_{\mathrm{N}}$ phase in $\mathrm{Ni}-\mathrm{Cr}$ alloys and the key role played by $\mathrm{Cr}$ in the formation of such phases [13].

The present research seeks to increase the limited knowledge regarding to the tribology and corrosion behaviour of nitrided superalloys and in particular, to compare and contrast the properties of nitrided layers comprising nitride precipitates and supersaturated solid solution phases. The paper also aims to investigate the improvement of Inconel 718 surface properties through the plasma-assisted process of Plasma Immersion Ion Implantation (PIII). The treatment of Inconel 718 by this process has shown to produce substantial incorporation of nitrogen in its surface.

\section{Experiment}

The superalloy Inconel 718 used in this work was provided by Villares S.A. (Sumare-Brazil). The material was melted in a VIM furnace, re-melted in a VAR furnace, followed by homogenization heat treatment, hot forging in a plain open die for drafting, hot rolling for drafting and a hot rolling finish. Table I shows the composition of the superalloy Inconel 718 used in this work.

Table I. Chemical composition (wt\%) of superalloy Inconel 718.

\begin{tabular}{|c|c|c|c|c|c|c|c|}
\hline $\mathbf{N i}$ & $\mathbf{F e}$ & $\mathbf{C r}$ & $\mathbf{M o}$ & $\mathbf{T i}$ & $\mathbf{A l}$ & $\mathbf{N b}$ & $\mathbf{C}$ \\
\hline 53.40 & 18.80 & 18.60 & 3.00 & 1.00 & 0.50 & 5.10 & 0.03 \\
\hline
\end{tabular}

PIII experiments were carried out at Laboratório Associado de Plasma - LAP - at Instituto Nacional de Pesquisas Espaciais - INPE. The samples were prepared as disks of $10 \mathrm{~mm}$ in diameter by $2.0 \mathrm{~mm}$ in thickness. The plasma chamber was initially pumped down to $\sim 3 \times 10^{-5}$ mbar (Figure 1). Next the nitrogen was introduced to produce the plasma by a glow discharge and the RUP-4 pulser was turned on to carry out the treatments.

The temperatures of the samples during the treatments were carefully monitored using a RAYTEK infrared pyrometer, sensitive in the $250-2000^{\circ} \mathrm{C}$ range. The heating of the samples is caused by the bombardment of the ions of the samples holder. The maximum temperature for the conditions used in these implantation processes was $290^{\circ} \mathrm{C}$.

The composition of the surface of the superalloy before and after implantation PIII was investigated by X-ray diffraction (XRD) technique using a Philips-X'Pert high resolution diffractometer with monochromatic $\mathrm{Cu} \mathrm{K \alpha}$ radiation.

Ion implantation (PIII) was carried out on samples of Inconel 718 for one hour and 3 hours at a pressure of $6.5 \times 10^{-3}$ mbar. Measurements of the dry friction coefficient were made using a CSM-Instruments Pin-on-disk Tribometer, computer controller SN 18-313, with $5 \mathrm{~cm} / \mathrm{s}$ of linear speed $(\sim 150 \mathrm{rpm}), 1.0 \mathrm{~N}$ of applied load and at room temperature. A $3.0 \mathrm{~mm}$ of wear track radius is choosed, stopping at 5000 revolutions running. Alumina $\left(\mathrm{Al}_{2} \mathrm{O}_{3}\right)$ balls with $3 \mathrm{~mm}$ diameter, 
polycrystalline, $99.8 \%$ purity, supplied by CSM-instruments, were used as a counter sample and were chosen for these tribological tests.

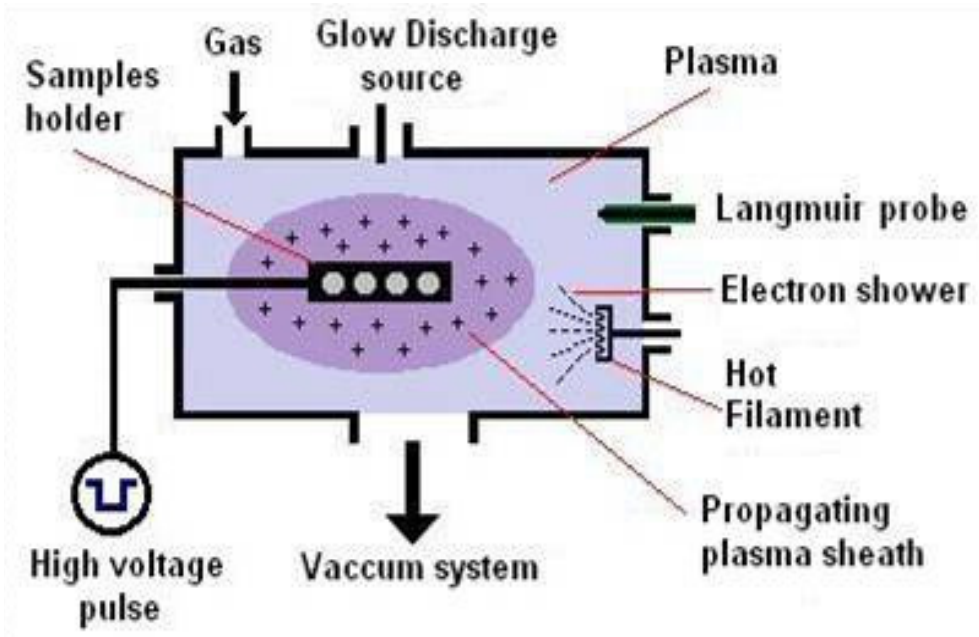

Figure 1 - Schematic diagram of PIII [14].

The experimental conditions for the PIII treatment are presented in Table II.

Table II - Experimental conditions used.

\begin{tabular}{|l|c|c|}
\hline \multicolumn{1}{|c|}{ Samples } & a) & b) \\
\hline Plasma potential $(\mathrm{V})$ & 90 & 90 \\
\hline Duration $($ min.) & 60 & 180 \\
\hline Pressure $($ mbar) & $6.5 \times 10^{-3}$ & $6.5 \times 10^{-3}$ \\
\hline High voltage $(\mathrm{kV})$ & 15 & 15 \\
\hline Pulse $(\mu \mathrm{s})$ & 40 & 40 \\
\hline Frequency $(\mathrm{Hz})$ & 300 & 30 \\
\hline
\end{tabular}

Disk volume loss and wear rate were calculated according to equation 1, from ASTM G99 norm [15]:

$$
V_{\text {lost }}=2 \pi R\left[r^{2} \sin ^{-1}\left(\frac{d}{2 r}\right)-\left(\frac{d}{4}\right)\left(4 r^{2}-d^{2}\right)^{1 / 2}\right],
$$

where:

$\mathrm{V}_{\text {lost }}$ - loss in volume;

d- track width; and

$\mathrm{r}-$ pin radius;

and 


$$
K=\frac{V_{\text {lost }}}{N . L}
$$

$\mathrm{V}_{\text {lost }}$ - loss in volume;

$\mathrm{N}$ - covered distance; and

$\mathrm{L}$ - applied load.

\section{Results and Discussion}

Fig. 2 shows X-ray diffraction (XRD) results for samples of Inconel 718, with and without nitrogen PIII implantation. Fig.2(a) showns the XRD of a reference sample. For one-hour implantation, XRD showns no new peaks because there is a very low concentration of implanted nitrogen. In this case, the implanted nitrogen could be observed only by EDS analysis Fig. 3. In the three-hour implantation case [Fig.2(c)], effect nitrogen implantation effect can be observed as new peaks, possibly of $\gamma_{\mathrm{N}}$ mixed with other phases.

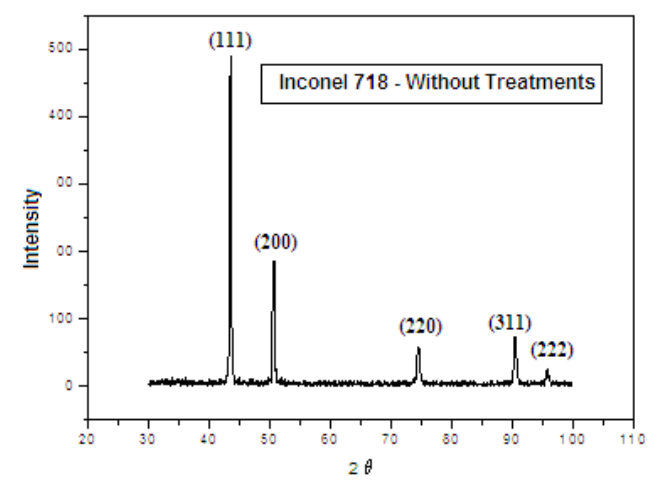

(a)

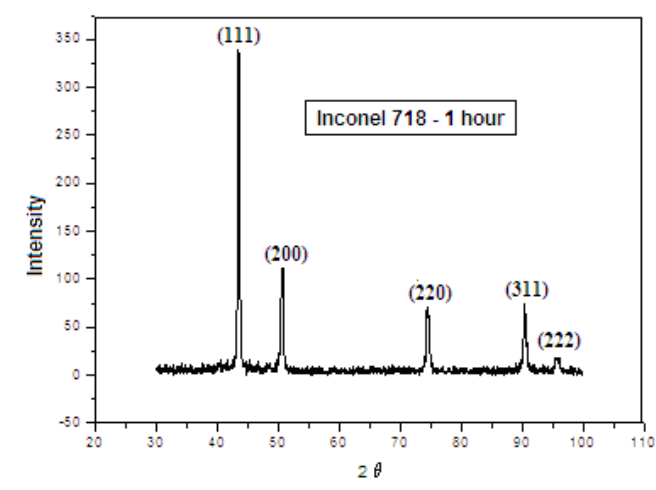

(b)

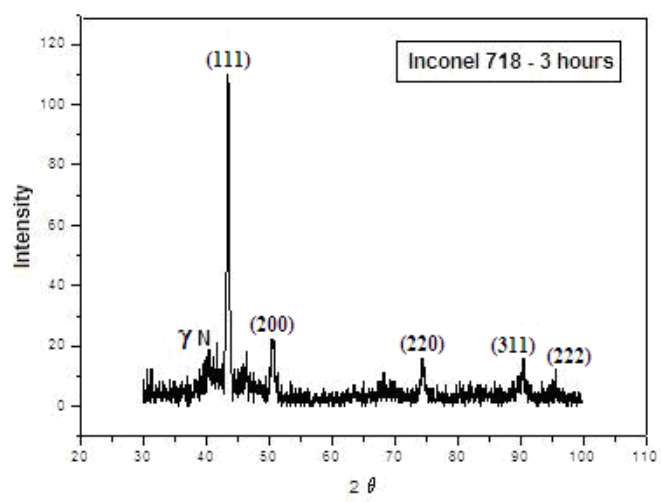

(c)

Figure 2 - X-ray diffraction of PIII treated Inconel 718: (a) without treatment; (b) treated for 1 hour; (c) treated for 3 hours. 


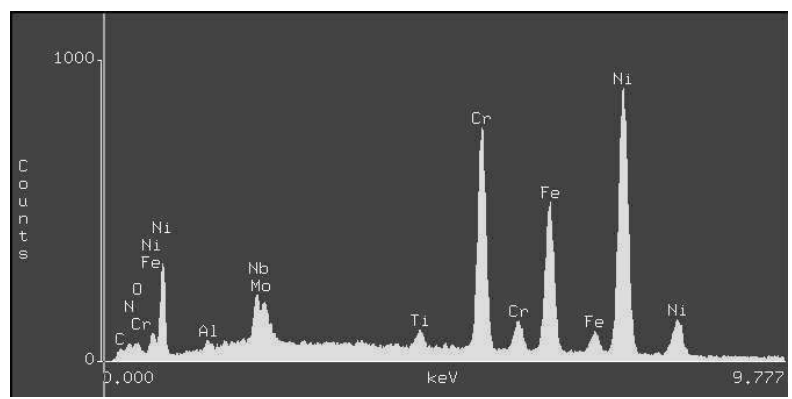

(a)

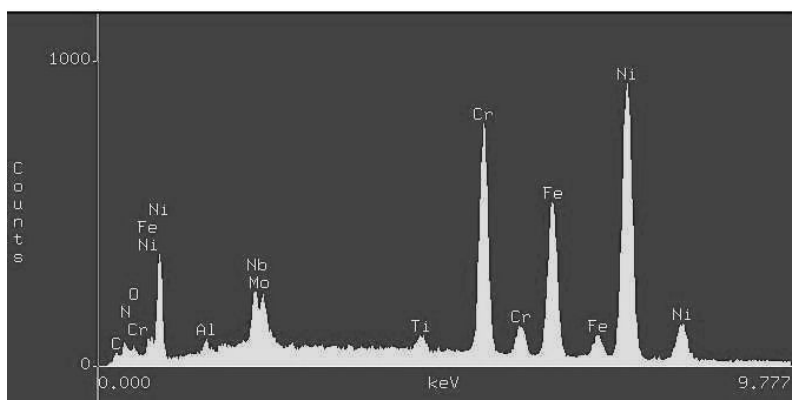

(b)

Figure 3- Energy dispersive spectroscopy (EDS) of PIII treated Inconel 718: (a) treated for 1 hour; (b) treated for 3 hours.

Fig. 4 shows the results of pin-on-disk wear test for untreated and treated samples, for one and three hours.

The untreated sample presents friction coefficient values $(\mu)$ of around $0.60-0.70$, right from the beginning of the test. The friction coefficient of treated sample for one hour starts at 0.2 and grows fast to 0.55 leveling off at around 0.50 . For the sample of 3 hour treatment, it starts at 0.1 , grows slowly to $0.3-0.35$ until reaching 4000 turns, when due to the reduction of the thickness of the modified layer by wear occurs and the friction coefficient finally rises to values closer to the ones for untreated sample. When the layer is completely worn out, the friction coefficient will reach the value of the reference sample, which did not happen for the number of cycles used in the testing.

Hence the pin-on-disk testing confirms the improved surface tribological properties for Inconel 718 after IIIP treatment. Comparing both conditions of treatment, however, the sample treated for three hours presents better resistance to wear as shown by its wear profile, discussed next.

Fig. 5 shows the wear profiles of the tracks after the wear testing of the material in the three conditions under discussion (reference, treated for one hour, and treated for three hours). Using these data, losses in volume (equation 1) and wear rate (equation 2) could be calculated, and are presented in Table III. 


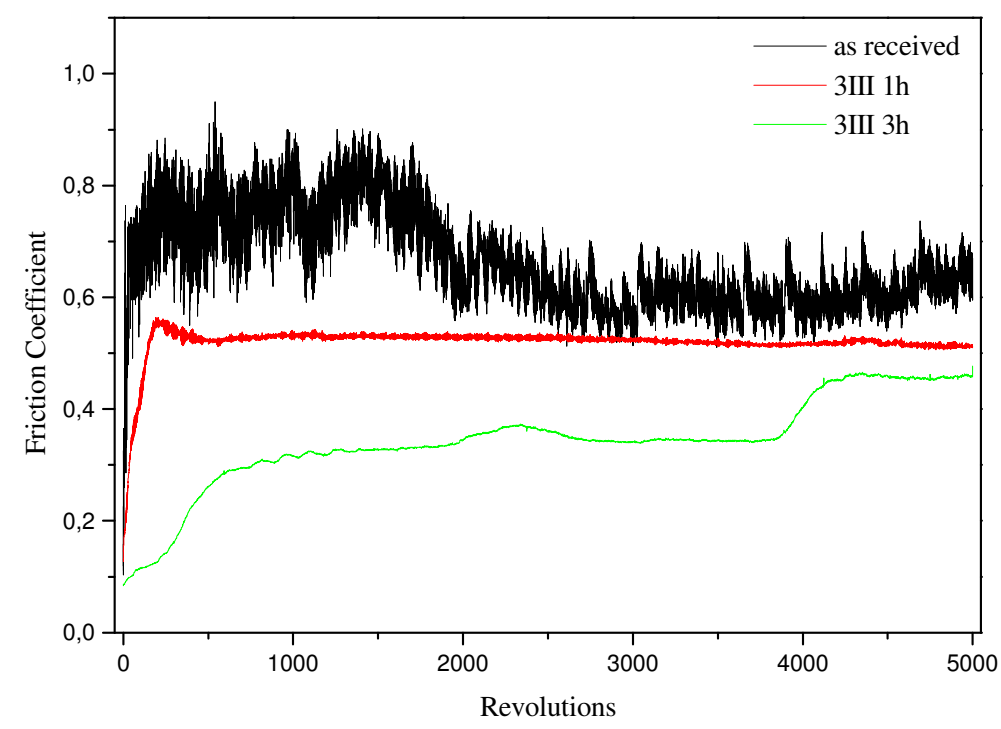

Figure 4 - Friction coefficient for Inconel 718 samples.

Note that the sample reference presents a lot of wear in comparison to the samples treated by PIII, showing a track width $(289.6 \mu \mathrm{m})$ seven to eight times larger than the samples treated for one hour $(36.1 \mu \mathrm{m})$ and 3 hours $(42.1 \mu \mathrm{m})$, respectively. The depth of the track $(60,000 \AA)$ is 40 times greater than the untreated samples when compared to the samples implanted with nitrogen (approximately 1,500 ̊).

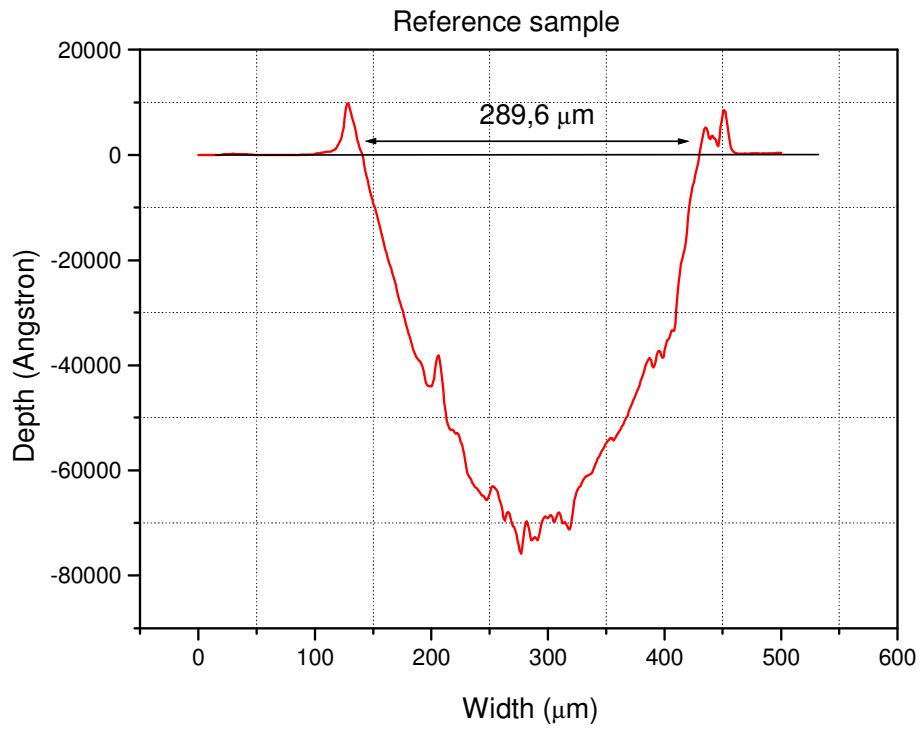

(a) 


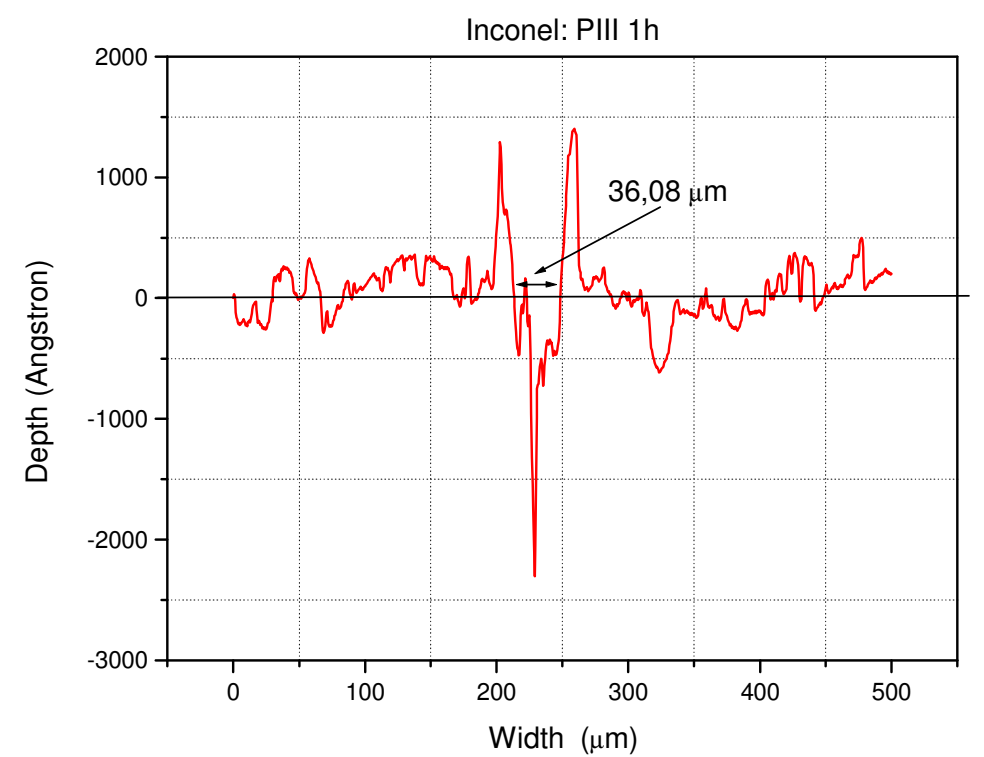

(b)

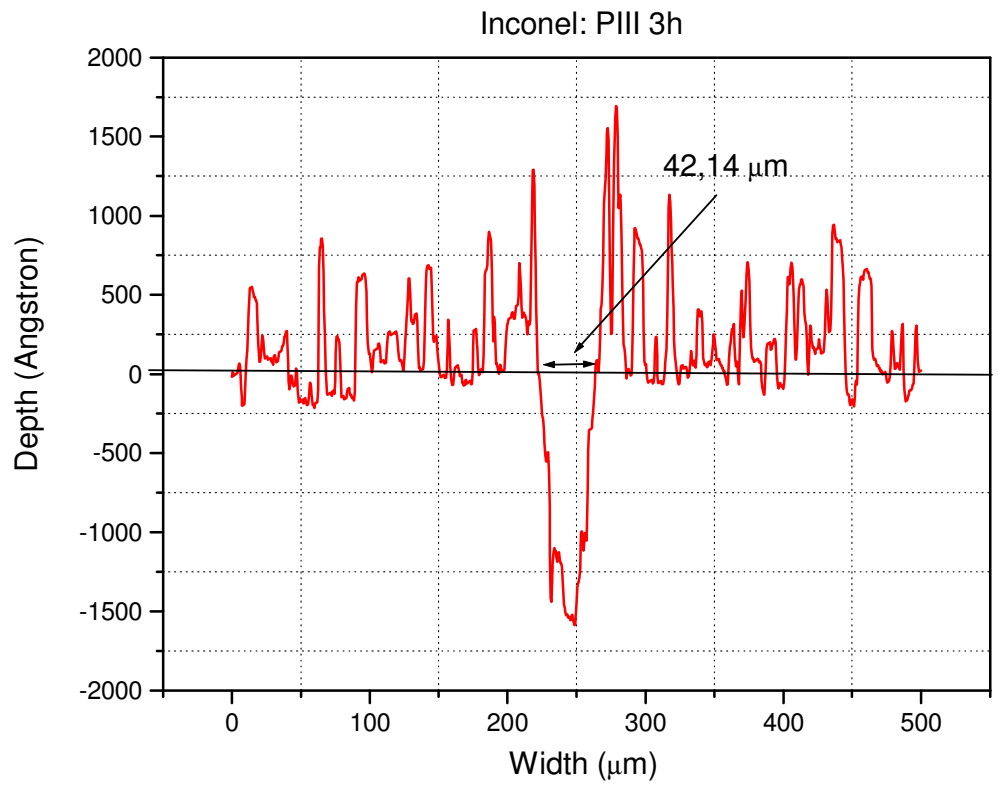

(c)

Figure 5 - Profiles of wear scars for Inconel 718 samples treated by nitrogen PIII.

Table III - Wear rate of Inconel 718 samples treated by nitrogen PIII.

\begin{tabular}{|l|c|c|c|}
\hline \multicolumn{1}{|c|}{ Inconel 718 } & $\begin{array}{c}\mathrm{d} \\
(\mathrm{mm})\end{array}$ & $\begin{array}{c}\mathrm{V} \\
\left(\text { loss in volume, } \mathrm{mm}^{3}\right)\end{array}$ & $\begin{array}{c}\text { Wear rate, } \\
\mathrm{mm} / \mathrm{N} . \mathrm{m}\end{array}$ \\
\hline Untreated & 0.289 & 230.75 & 1.85 \\
\hline 1 hour & 0.036 & 28.70 & 0.29 \\
\hline 3 hours & 0.042 & 33.40 & 0.35 \\
\hline
\end{tabular}


Losses in volume during the wear testing on the sample that was not treated $\left(230.5 \mathrm{~mm}^{3}\right)$ are much greater than the one for the samples treated by PIII, about eight times for the sample treated for one hour $\left(28.7 \mathrm{~mm}^{3}\right)$ and approximately seven times for the sample treated for three hours $\left(33.4 \mathrm{~mm}^{3}\right)$. These last two results would appear to contradict the expectations, since the three-hour sample presents a lower friction coefficient. Consequently it would expect greater resistance to wear, less losses in volume and a lower wear rate. This is probably due to errors that could have been caused given the difficulty of accurately measuring small wear tracks, associated with the increased surface roughness of the alloy after IIIP treatment. This increased unevenness caused by IIIP treatment has been previously observed by our research group, as well as by other researchers [16].

These results are in partial agreement with Batchelor et al. [17] who reported a reduction in friction for plasma nitrided Inconel 718 pins sliding against untreated Inconel 718 drums [17]. In that study, however, wear was not reduced due to fracture of the CrN-rich layer.

Shanov and Tabokoff [18] reported that plasma nitriding Inconel 718 at $520^{\circ} \mathrm{C}$ for $7 \mathrm{~h}$ did not increase erosion resistance, but in contrast to Batchelor et al. [17], claimed that ductile behaviour was observed in the nitrided layers.

\section{Conclusion}

This paper have shown that PIII is a versatile and attractive surface modification method for the improvement of tribological properties of Inconel 718.

For one-hour implantation XRD it is showed that there is no new peaks besides ones seen in untreated Inconel because there is a very low concentration of implanted nitrogen. For onehour implantation, the implanted nitrogen could be observed only by Energy dispersive spectroscopy EDS analysis. In the three-hour implantation case, new phases can be observed in the $\mathrm{x}$-ray diffraction technique.

Major improvements for Inconel 718 samples treated for 3 hours are its wear resistance and reduction in the friction coefficient, caused by nitrogen PIII.

\section{Acknowledgements}

The authors wish to thank $\mathrm{CNPq}$ for the financial support in this work, the Aeronautics Technological Institute (ITA), Vale Soluções em Energia (VSE) and National Institute for Space Research (INPE).

\section{References}

1. Sims T.S., Stoloff N. and Hagel W.C. Superalloys II High Temperature. Materials for Aerospace and Industrial Power, ed. John Willey, New York, 1987.

2. Giampaolo T. The gas turbine handbook: Principles and practices. $2^{\text {nd }}$ edition, Marcel Dekker, Inc. 2002.

3. Barbosa C. et al., Microstructural aspects of the failure analysis of nickel base superalloys components. Engineering Failure Analysis v.12 p. 348-361, 2005.

4. Ezugwu E.O, Wang Z.M., and Machado A.R. The machinability of nickel-based alloys: a review, Journal of Materials Processing Technology, v. 86, p.1-16, 1999. 
5. Xingfu Y., Sugui T and Minggang W. Creep behavior and effect factors of single crystal nickel-base superalloys. Materials Science and Engeneering A, v. 499, p.352-359, 2009.

6. Hirschmann A.C.O., Reis D.A. and Moura Neto, C. Basic fundamental of superalloys. $64^{\text {th }}$ Congress of the Brazilian Association for Metals, Materials and Mining - ABM, Brazil, 2009.

7. Pineau A. High temperature fatigue: creep-fatigue-oxidation interactions in relation to microstructure. Subcritical crack growth due to fatigue stress corrosion and creep. London Elsevier 1984 p.483-530.

8. Jones J., Mackay D.J. and Bhadeshia K. The Strength of Ni-base Superalloys Bayesian Neural Network Analysis. Proceedings of the $5^{\text {th }}$ International Symposium on Advanced Materials, Pakistan, p 659-666, 1995.

9.. Rubly R.P and Douglass L.D., Internal nitridation of nickel-chromium alloys, Oxidation Metals v. 35, p.259-278, 1991.

10 Kodentsov A. A., Van Dal M.J.H. and Cserháti C., Permeation of nitrogen in solid nickel and deformation phenomena accompanying internal nitridation, Acta Materialia v. 47 p. 3169 3180, 1999.

11. Dearnley P.A., et al., Some observations on plasma nitriding austenitic stainless steel, in: E. Broszeit (Ed.), Plasma Surface Engineering, Proceedings of the $1^{\text {st }}$ International Conference on Plasma Surface Engineering, Garmisch-Partenkirchen, 1989, pp. 219-226.

12. Collins G.A., et al., Nitriding of austenitic stainless steel by plasma immersion ion implantation, Surf. Coat. Technol. 74-75 (1995) 417-424.

13. Williamson D.L., et al., Metastable phase formation and enhanced diffusion in FCC alloys under high dose, high flux nitrogen implantation at high and low ion energies, Surf. Coat. Technol. 65 (1994) 15-23.

14. Silva M.M. and Ueda M. Modificação de propriedades superficiais da liga de Ti-6Al-4V por processo assistido plasma, em baixas e altas temperaturas. Doctorate Thesis, ITA/DCTA São José dos Campos, 2007.

15. G 99 - Standard Test Method for wear Testing with a pin-on-disk Apparatus in ASTMStandarts, 2000.

16. Silva, M. M.; Ueda, M. and Mello, C. B. Wear Resistance Study of Ti-6Al-4V Treated by Plasma Immersion Ion Implantation at Low and High Temperatures. In: VI Encontro SBPMat, 2007, Natal.

17. Batchelor A.W. and Loh N.L., Failure mechanisms of plasma nitrided Inconel 718 film, Wear 208 (1997) 226-236.

18. Shanov V. and Tabakoff W., Erosion resistance of coatings for metal protection at elevated temperatures, Surf. Coat. Technol. 86-87 (1996) 88-93. 